\title{
SEROPREVALENCE OF TOXOPLASMA GONDII INFECTION AND ITS AS- SOCIATED RISK FACTORS IN NEUROPSYCHIATRIC PATIENTS IN JAZAN PROVINCE, SAUDI ARABIA
}

\author{
By \\ WAFAA M. ZAKI ${ }^{1,2}$, RASHA Y. HOFDI ${ }^{2}$, AISHA A. SHEBILEY ${ }^{2}$, \\ ZAKI A. SAADI ${ }^{3}$, and ALI H. AGEEL ${ }^{3}$
}

Department of Medical Parasitology ${ }^{1}$, Faculty of Medicine, Suez Canal University, Egypt, Department of Medical Laboratory Technology ${ }^{2,3}$, Faculty of Applied Medical Science, Jazan University ${ }^{2}$ and Al-Amal Hospital for Psychiatric Health ${ }^{3}$, Jazan, Saudi Arabia (*Correspondence: wafaa_zaki@hotmail.com)

\begin{abstract}
Toxoplasma gondii has worldwide distribution in nearly one-third of the human population. It is a neurotropic protozoan parasite so a potential role of $T$. gondii infection for some neuropsychiatric disorders was postulated. Patients with psychiatric disorders had high toxoplasmosis seroprevalence. Limited information about toxoplasmosis seroprevalence in psychiatric patients was known in southern area of Saudi Arabia.

The current cross sectional case control study aims at determination of the prevalence of $T$. gondii IgG \& IgM in neuropsychiatric patients in Jazan Province. A total of 162 neuropsychiatric patients from Al-Amal hospital for psychiatric health and 162 subjects without neuropsychiatric manifestations from Jazan General Hospital, Jazan City, KSA. were enrolled in the study. Psychiatric diagnosis was based on the International Classification of Diseases-10 (ICD-10 classification). Serological analysis for latent toxoplasmosis (IgG) and active toxoplasmosis (IgM) was done using Enzyme Linked Immunosorbent Assay (ELISA). Investigations for the association with socio-demographic, clinical and behavioral characteristics in psychiatric patients were also done.

The serofrequency of IgG antibodies among neuropsychiatric patients was significantly higher than that of the controls $(35.8 \%$ vs $14.8 \%) \mathrm{P}=0.0022$. OR 3.2 with $95 \% \mathrm{CI}=$ (1.4952 to 6.8774). However; serofrequency of toxoplasma IgM antibody between neuropsychiatric patients and controls was not statistically significant $(P>0.05)$. Bivariate and multivariate analysis for socio-demographics and possible associated risk factors showed that contact to cats and/or dogs, eating under cooked meat, and contact to soil were significantly higher in neuropsychiatric patients than controls.
\end{abstract}

Keywords: Toxoplasma gondii, Neuropsychiatric patients, ELISA.

\section{Introduction}

Toxoplasma gondii is an obligate opportunistic intracellular protozoan parasite which belongs to the phylum Apicomplexa, order Coccidia (Rorman et al, 2006). It can infect almost all warm-blooded animals, including humans (Zhou et al, 2011). T. gondii infection was estimated to be about onethird of the human population in the world (Dubey et al, 2010). Human infection is mainly acquired by special routes which include ingestion of contaminated food or water and eating undercooked or raw meat that contains tissue cysts. Less commonly, it is associated with blood transfusion or organ transplantation (Alvarado-Esquivel et al, 2010). Meanwhile infection in immunocompetent persons does not cause serious illness; it is kept in its latent stage by the host's immune system and clinical manifestations are often not apparent. However; in congenital infection, blindness and mental retardation in children can result (Hamidinejat et al, 2010). The disease can be severe in immunocompromised patients e.g., AIDS patients, patients after transplantation and patients under corticosteroids or anticancer therapy. Latent toxoplasmosis can be transformed into its active form resulting in toxoplasmic encephalitis, which is often fatal (Jones et al, 
2001).

Toxoplasma gondii has a neurotropic nature, this nature and other features may help in pathogenic mechanisms implicating in mental and behavioural disorders (Flegr, 2015). T. gondii uses a complex mechanism to gain access to the brain with preferred sites at cerebral hemispheres, basal ganglia, cerebellum and brain stem (Carruthers and Suzuki, 2007). Once enters CNS, it invades various brain cells, including astrocytes and neurons, where it forms cysts containing bradyzoites. Then, it can establish a continuous infection within the CNS, influencing host behaviour, and can cause neurological and psychiatric symptoms in some infected individuals (Fabiani et al, 2013). Many toxoplasmic immunological reactions and reactivation mechanisms led to behavioral disorders in man (Fekadu et al, 2010). Subjects with various neuropsychiatric disturbances, as schizophrenia (Alvarado-Esquivel et al, 2006) personality disorders, obsessive compulsive disorder (Alvarado-Esquivel et al, 2015b), bipolar disorder, unipolar depression, drug abuse disorder, suicides, homicides, generalized anxiety, panic disorders and mood disturbances, have been reported to be more often infected with Toxoplasma than normal controls (Flegr, 2015). Behavioral disorders due to psychoactive substances are also reported in toxoplasmosis patients (Alvarado-Esquivel et al, 2015a). T. gondii infection proved to have a role in traffic accidents, work accidents, and mental illnesses (Alvarado-Esquivel et al, 2015b).

This present study was conducted to estimate the seroprevalence of $T$. gondii infection, and identify its risk factors and possible contamination routes in a population of psychiatric patients in Jazan, KSA.

\section{Subjects, Materials and Methods}

This is a cross-sectional, case control study examining the serofrequency of $T$. gondii among patients with neuropsychiatric disorders. A total of 162 patients suffering from psychological and/or neurological dis- orders attended Al-Amal hospital for psychiatric health, Jazan were investigated for presence of T.gondii IgG and IgM antibodies. Furthermore, the correlation between $T$. gondii infection and the socio-demographic, clinical and behavioral characteristics of the patients was also investigated.

A uniformly structured questionnaire was fulfilled by the patients to obtain their sociodemographic, clinical, and behavioral features. The socio-demographic data included age, gender, residence, urban or rural habitation, marital status, educational level, occupation, and socioeconomic status. Regarding the clinical features, the following data were investigated: health status, history of lymphadenopathy, blood transfusions, transplantation and surgeries, presence of frequent headache, dizziness, and impairments in vision, hearing, memory and reflexes. In female patients, obstetric history was also obtained. In addition, history of aggressiveness, suicidal ideation and suicide attempt were also collected from each study subject. Psychiatric diagnosis was based on the ICD10 classification (WHO, 1992). Information on potential risk factors such as direct contact with cats or dogs or litter's box, contact with other animals, eating behavior like consumption of raw or undercooked meat and its frequency, consumption of unwashed raw vegetables and fruits, contact with soil, and type of flooring at home.

Five $\mathrm{mL}$ of venous blood was collected aseptically from 162 neuropsychiatric patients (subjects) from Al- Amal hospital for psychiatric health, Jazan and 162 subjects without neuropsychiatric manifestations (controls) from Jazan General Hospital during the period between September 2015 to May 2016. The serum was separated from the whole blood by centrifugation at 3000 rpm for ten minutes at room temperature. The separated serum was labeled and kept at $-20 \circ \mathrm{C}$ until tested for anti-T. gondii $\mathrm{IgG}$ and IgM antibodies using ELISA test kit (Human Gesllschaft for biochemical and diagnostic, Max Plank, Germany) following the 
manufacturer's instruction. Samples absorbance were read using microtiter plate reader at absorbance of $450 / 620 \mathrm{~nm}$. The sera of both patients and controls were obtained from blood at the time of interviews. Each sample was tested in duplicate to ensure reliability. All experiments were done in strict sterile conditions.

Statistical analysis: Results were analyzed using Statistical Package for Social Sciences (SPSS) version 20 (Chicago, Illinois, USA). Sserofrequency of $T$. gondii IgG \& IgM antibodies were calculated by descriptive statistics (frequencies), and the differences between the groups were calculated using the Chi-square, Student's t-test or Fisher's exact test. Odd ratio (OR) and its 95\% Confident Interval (CI) were used to estimate the association between $T$. gondii and neuropsychiatric disorder. Bivariate and multivariate logistic regression analysis was done for demographic data and associated risk factors.

Ethical considerations: All enrolled participants were informed with the aim of the study and an approval form was used to obtain written informed consent from each of them or their guardians. Seropositive patients were informed with their results and appropriate treatment was prescribed by the concerned physician.

\section{Results}

Individuals with neuropsychiatric disorder had significantly increased levels of serum IgG antibodies to $T$. gondii 58/162 (35.8\%) when compared to controls 24/162 (14.8\%), $P=0.0022$. The $\mathrm{OR}$ for this association was 3.2 with $95 \% \mathrm{CI}=1.4952$ to 6.8774 . Meanwhile, the $\operatorname{IgM}$ antibody was found in $10 / 162(6 \%)$ of patients with neuropsychiatric disorders and 6 subjects $(3.7 \%)$ in control group. The difference is statistically insig- nificant, $P=0.497$; OR 1.7105 , CI 0.3949 to 7.4085 (Tab. 1). The demographic profiles of the patients with neuropsychiatric disorders and controls were compared (Tab. 2). The mean ages of patients and controls were $35.3 \pm 9.1$ years (range; 19-67 years) and $34.7 \pm 8.9$ years (17-64 years) respectively. The duration of illness for patients was 3.6 \pm 1.4 years (1.0-9.0 years). Non-working status was significantly higher $(P=0.005)$ among IgG positive patients $(42.5 \%)$ compared to IgG positive controls (18.9\%).

The majority of IgG positive patients $(45.9 \%)$ had duration of education less than 12 years and $(47.5 \%)$ belonged to low socioeconomic state. However, both gender and marital status have no significant differences between patients and control $P=0.643$ and $P=0.566$ respectively. The most prevalent neuropsychiatric disorder was schizophrenia patients (Tab. 3).

Bivariate analysis (Tab. 4) showed association between some sociodemographic characteristics and some behavioural characteristics in neuropsychiatric patients, including pet cats or dogs, consumption of raw vegetables and fruit, consumption of raw/ undercooked meat and exposure to soil. Multivariate analysis of sociodemographic and behavioral characteristics (Tab. 5) showed that exposure to soil led to highly significant differences between cases and control [adjusted OR (aOR) 7.31; 95\% CI 3.6-15.1; $P=$ $0.001]$. Also, cats indoors showed [(aOR) $6.17,95 \%$ CI $3.411-10.715, P=0.001]$ and the consumption of raw/undercooked meat [aOR 0.26; 95\%CI 0.10-0.63; $P=0.002$ ] were significantly associated with increased Toxoplasma IgG seroprevalence in neuropsychiatric patients. Other behavioral characteristics did not show association with $T$. gondii infection.

Table1: Seroprevalence of IgG \& IgM antibodies to T. gondii in neuropsychiatric patients \& controls.

\begin{tabular}{|c|c|c|c|c|c|c|}
\hline Immunogloblin & \multicolumn{2}{|c|}{ Neuropsyciatric patients $(n=162)$} & \multicolumn{2}{|c|}{ Control $(n=162)$} & \multirow{2}{*}{$\begin{array}{c}\mathrm{P} \\
\text { value }\end{array}$} & \multirow{2}{*}{$\begin{array}{c}\text { OR (95\% confidence } \\
\text { interval) }\end{array}$} \\
\hline & No & $\%$ & No & $\%$ & & \\
\hline IgG positive & 58 & 35.8 & 24 & 14.8 & 0.0022 & $3.2067(1.4952$ to 6.8774$)$ \\
\hline IgG negative & 104 & 64.1 & 138 & 85.2 & & \\
\hline IgM positive & 10 & 6 & 6 & 3.7 & 0.497 & $1.7105(0.3949$ to 7.4085$)$ \\
\hline IgM negative & 152 & 94 & 156 & 96.3 & & \\
\hline
\end{tabular}


Table 2: Socio-demographic characters and seroprevalence of $T$. gondii IgG antibodies in studied subjects.

\begin{tabular}{|c|c|c|c|c|c|c|c|c|c|c|}
\hline \multicolumn{2}{|c|}{ Demographic data } & \multicolumn{4}{|c|}{ Neuropsyiacatric patients } & \multicolumn{3}{|c|}{ Controls } & \multirow[b]{2}{*}{$\%$} & \multirow[t]{2}{*}{$\mathrm{P}$ value } \\
\hline & & $\mathrm{n}=162$ & $\%$ & IgG +ve & $\%$ & $\mathrm{~N}=162$ & $\%$ & IgG +ve & & \\
\hline \multirow{4}{*}{ Age } & $20-29$ & 22 & 13.6 & 3 & 13.6 & 24 & 14.8 & 2 & 8.3 & 0.5677 \\
\hline & $40-49$ & 41 & 25.3 & 15 & 36.6 & 47 & 29 & 8 & 17 & 0.0379 \\
\hline & $50-59$ & 36 & 22.2 & 18 & 50 & 30 & 18.5 & 6 & 20 & 0.0123 \\
\hline & $60-69$ & 23 & 14.2 & 13 & 56.5 & 23 & 14.2 & 5 & 21.7 & 0.6638 \\
\hline \multirow[t]{2}{*}{ Sex } & Male & 94 & 58 & 34 & 36.2 & 94 & 58 & 16 & 67 & \multirow{2}{*}{0.643} \\
\hline & Female & 68 & 42 & 24 & 35.3 & 68 & 42 & 8 & 33 & \\
\hline Working status & $\begin{array}{l}\text { Working } \\
\text { Not working }\end{array}$ & $\begin{array}{l}89 \\
73\end{array}$ & $\begin{array}{l}55 \\
45\end{array}$ & $\begin{array}{l}27 \\
31\end{array}$ & $\begin{array}{l}30.3 \\
42.5\end{array}$ & $\begin{array}{c}109 \\
53\end{array}$ & $\begin{array}{l}67.3 \\
32.7\end{array}$ & $\begin{array}{l}14 \\
10\end{array}$ & $\begin{array}{l}12.8 \\
18.9\end{array}$ & 0.005 \\
\hline Marital status & $\begin{array}{l}\text { Married } \\
\text { Single/widow/divorced }\end{array}$ & $\begin{array}{c}108 \\
54\end{array}$ & $\begin{array}{l}66.7 \\
33.3 \\
\end{array}$ & $\begin{array}{l}37 \\
21 \\
\end{array}$ & $\begin{array}{l}34.3 \\
38.9 \\
\end{array}$ & $\begin{array}{c}119 \\
43\end{array}$ & $\begin{array}{l}73.5 \\
26.5\end{array}$ & $\begin{array}{c}15 \\
9\end{array}$ & $\begin{array}{l}42 \\
58 \\
\end{array}$ & 0.5661 \\
\hline Educational level & $\begin{array}{l}\text { (>12years education } \\
\text { ( } \leq 12 \text { years education) }\end{array}$ & $\begin{array}{l}75 \\
87 \\
\end{array}$ & $\begin{array}{l}46.3 \\
53.7\end{array}$ & $\begin{array}{l}18 \\
40\end{array}$ & $\begin{array}{c}24 \\
45.9 \\
\end{array}$ & $\begin{array}{c}114 \\
48\end{array}$ & $\begin{array}{l}70.4 \\
29.6\end{array}$ & $\begin{array}{l}13 \\
11 \\
\end{array}$ & $\begin{array}{l}11.4 \\
22.9\end{array}$ & 0.003 \\
\hline $\begin{array}{l}\text { Illness duration } \\
\text { in years }\end{array}$ & & $\begin{array}{c}1-9 \\
3.6 \pm 1.4\end{array}$ & & & & ------- & & & & \\
\hline Age & $\begin{array}{l}\mathrm{M} \pm \mathrm{SD} \\
\text { Range }\end{array}$ & $\begin{array}{c}35.3 \pm 9.1 \\
19-67 \\
\end{array}$ & & & & $\begin{array}{c}34.7 \pm 8.9 \\
17-64 \\
\end{array}$ & & & & \\
\hline
\end{tabular}

Table 3: Seropositivity of anti-T. gondii IgG in 162 neuropsychiatric patients according to clinical diagnosis

\begin{tabular}{|l|c|c|c|c|c|}
\hline Neuropsychiatric disorder & ICD-10 & Patients No. & IgG +ve (\%) & $95 \%$ CI & P value \\
\hline Schizophrenia & F20 & 52 & $18(34.6 \%)$ & $0.6343-40.8180$ & 0.022 \\
\hline Drug induce Psychosis & F19 & 34 & $12(35.3 \%)$ & $2.6818-47.7685$ & 0.048 \\
\hline Mild depression & F32.051 & 24 & $4(16.7 \%)$ & $15.5931-34.3951$ & 0.864 \\
\hline Moderate depression & F32.151 & 10 & $6(60 \%)$ & $1.1485-8.6073$ & 0.010 \\
\hline Obsessive compulsive disorder & F42 & 8 & $2(25 \%)$ & $6.0034-16.2164$ & 0.582 \\
\hline Major depressive disorder & F32.251 & 6 & $2(33.3 \%)$ & $15.3619-76.1724$ & 0.387 \\
\hline Epilepsy & G40 & 6 & $6(100 \%)$ & $17.6000-37.5683$ & 0.001 \\
\hline Mental retardation & F70-F71 & 4 & $2(50 \%)$ & $14.4846-54.4301$ & 0.178 \\
\hline Mental and behavioral disorders due to drug & F19 & 4 & $1(25 \%)$ & $36.4171-45.2742$ & 0.656 \\
\hline Alzheimer's disease & G30 & 4 & $2(50 \%)$ & $14.4846-48.4301$ & 0.178 \\
\hline Unspecified mental disorder & F99 & 4 & $1(25 \%)$ & $36.4171-45.2742$ & 0.656 \\
\hline Drug induce Parkinsonism & G21.1 & 4 & $2(50 \%)$ & $14.4846-48.4301$ & 0.178 \\
\hline Depressive conduct disorder & F92.0 & 2 & $0(0 \%)$ & $24.4316-52.9449$ & 0.679 \\
\hline Total & & 162 & $58(35.8 \%)$ & 1.4952 to 6.8774 & 0.0022 \\
\hline
\end{tabular}

as compared with $14.8 \%$ seroprevalence of anti-T. gondii $\mathrm{IgG}$ antibodies in controls (24/162).

Table 4: Bivariate logistic regression analysis of risk factors associated with $T$. gondii among studied subjects.

\begin{tabular}{|c|c|c|c|c|c|c|c|c|c|c|c|c|c|}
\hline \multirow{2}{*}{\multicolumn{2}{|c|}{ Character }} & \multicolumn{4}{|c|}{ Neuropsychaitric patients } & \multicolumn{4}{|c|}{ Control subjects } & \multicolumn{4}{|c|}{ Total } \\
\hline & & $\mathrm{No}$ & IgG & 0 & P & $\mathrm{No}$ & IgG & 0 & P & $\mathrm{No}$ & IgG & 0 & P \\
\hline Residence & $\begin{array}{l}\text { Urban } \\
\text { Rural }\end{array}$ & $\begin{array}{l}94 \\
68\end{array}$ & $\begin{array}{l}37 \\
21\end{array}$ & $\begin{array}{l}39.4 \\
30.9\end{array}$ & 0.267 & $\begin{array}{l}91 \\
71\end{array}$ & $\begin{array}{c}15 \\
9\end{array}$ & $\begin{array}{l}16.5 \\
12.7\end{array}$ & 0.501 & $\begin{array}{l}185 \\
139\end{array}$ & $\begin{array}{l}52 \\
30\end{array}$ & $\begin{array}{l}28.1 \\
21.6\end{array}$ & 0.184 \\
\hline Contact with cat $/$ dog & $\begin{array}{l}\text { Yes } \\
\text { No }\end{array}$ & $\begin{array}{l}97 \\
65\end{array}$ & $\begin{array}{l}45 \\
13\end{array}$ & $\begin{array}{c}46.4 \\
20\end{array}$ & 0.006 & $\begin{array}{l}80 \\
82\end{array}$ & $\begin{array}{c}19 \\
5\end{array}$ & $\begin{array}{c}23.8 \\
6.1\end{array}$ & 0.001 & $\begin{array}{l}177 \\
147\end{array}$ & $\begin{array}{l}64 \\
18\end{array}$ & $\begin{array}{l}36.2 \\
12.2\end{array}$ & $<0.0001$ \\
\hline $\begin{array}{l}\text { Eating raw undercooked } \\
\text { vegetables or fruits }\end{array}$ & $\begin{array}{l}\text { Yes } \\
\text { No }\end{array}$ & $\begin{array}{l}91 \\
71\end{array}$ & $\begin{array}{l}36 \\
22 \\
\end{array}$ & $\begin{array}{c}39.6 \\
31\end{array}$ & 0.259 & $\begin{array}{l}89 \\
73\end{array}$ & $\begin{array}{l}14 \\
10\end{array}$ & $\begin{array}{l}15.7 \\
13.7\end{array}$ & 0.722 & $\begin{array}{l}180 \\
144\end{array}$ & $\begin{array}{l}50 \\
32\end{array}$ & $\begin{array}{l}27.8 \\
22.2\end{array}$ & 0.250 \\
\hline $\begin{array}{l}\text { Eating raw/undercooked } \\
\text { meat }\end{array}$ & $\begin{array}{l}\text { Yes } \\
\text { No }\end{array}$ & $\begin{array}{l}86 \\
76 \\
\end{array}$ & $\begin{array}{l}38 \\
20\end{array}$ & $\begin{array}{l}44.2 \\
26.3 \\
\end{array}$ & 0.018 & $\begin{array}{l}78 \\
84\end{array}$ & $\begin{array}{c}17 \\
7\end{array}$ & $\begin{array}{c}21.8 \\
8.3\end{array}$ & 0.016 & $\begin{array}{l}164 \\
160\end{array}$ & $\begin{array}{l}55 \\
27\end{array}$ & $\begin{array}{l}33.5 \\
16.9 \\
\end{array}$ & 0.005 \\
\hline Contact with soil & $\begin{array}{l}\text { Yes } \\
\text { No }\end{array}$ & $\begin{array}{c}104 \\
58\end{array}$ & $\begin{array}{c}49 \\
9\end{array}$ & $\begin{array}{l}47.1 \\
15.5\end{array}$ & 0.001 & $\begin{array}{l}98 \\
64\end{array}$ & $\begin{array}{c}19 \\
5\end{array}$ & $\begin{array}{c}19.4 \\
7.8\end{array}$ & 0.043 & $\begin{array}{l}202 \\
122\end{array}$ & $\begin{array}{l}68 \\
14\end{array}$ & $\begin{array}{l}33.7 \\
11.5\end{array}$ & $<0.0001$ \\
\hline Past history of surgery & $\begin{array}{l}\text { Yes } \\
\text { No }\end{array}$ & $\begin{array}{c}59 \\
103 \\
\end{array}$ & $\begin{array}{l}19 \\
39 \\
\end{array}$ & $\begin{array}{l}32.2 \\
37.9 \\
\end{array}$ & 0.467 & $\begin{array}{c}53 \\
109 \\
\end{array}$ & $\begin{array}{c}8 \\
16 \\
\end{array}$ & $\begin{array}{l}15.1 \\
14.7 \\
\end{array}$ & 0.984 & $\begin{array}{l}112 \\
212 \\
\end{array}$ & $\begin{array}{l}27 \\
47 \\
\end{array}$ & $\begin{array}{l}24.1 \\
22.2 \\
\end{array}$ & 0.6989 \\
\hline History of blood transfusion & $\begin{array}{l}\text { Yes } \\
\text { No }\end{array}$ & $\begin{array}{c}29 \\
133\end{array}$ & $\begin{array}{l}17 \\
41\end{array}$ & $\begin{array}{l}58.6 \\
30.8\end{array}$ & 0.048 & $\begin{array}{c}24 \\
138\end{array}$ & $\begin{array}{c}6 \\
18\end{array}$ & $\begin{array}{c}25 \\
13.0\end{array}$ & 0.345 & $\begin{array}{c}53 \\
271\end{array}$ & $\begin{array}{l}23 \\
59\end{array}$ & $\begin{array}{l}43.4 \\
21.8\end{array}$ & 0.001 \\
\hline
\end{tabular}

Table 5: Multivariate logistic regression analysis of psychiatric patients' characteristics \& T. gondii infection.

\begin{tabular}{|l|c|c|c|}
\hline Characteristics & Adjusted Odd ratio & $95 \%$ C.I. & P value \\
\hline Residence area & 0.89 & $0.429-1.812$ & 0.691 \\
\hline Contact with cat and/or dog & 6.17 & $3.411-10.715$ & 0.001 \\
\hline Eating raw /undercooked meat & 0.26 & $0.10-0.63$ & 0.002 \\
\hline Contact with soil & 7.31 & $3.6-15.1$ & 0.001 \\
\hline History of blood transfusion & 0.94 & $0.61-1.67$ & 0.83 \\
\hline
\end{tabular}




\section{Discussion}

The mental and behavioral disorders have major public health problem. It affects about $10 \%$ to $16 \%$ of the population in any given year (Wang et al, 2007). Twelve percent of the global disease burden was shared by these disorders (WHO, 2001). The treatment is mostly symptomatic because the etiology is still obscure. Although it is hypothesized to be multifactorial and related to genetic and environmental mediation, there is a great assumption for the role of microbial agents in the causation of psychiatric disorders. The infectious agents take major part in attention, such as Toxoplasma gondii, herpes simplex virus, cytomegalovirus and influenza virus (Fekadu et al, 2010).

In the present study, a significant difference was found between neuropsychiatric patients $35.8 \%$ and controls $14.8 \%$ for $T$. gondii IgG. Regional variations in the incidence of $T$. gondii infection rates from one country to another or even within the same country, has been well documented. In different areas in Saudia Arabia, there was a diversity between levels, it was lower than our study in some areas: $21.3 \%$ in Almadinah Almunawwarah (Immam et al, 2016), $22.4 \%$ in Riyadh (Ahmed, 1992), 24.1\% in Jazan (Aqeely et al., 2014), 29.4\% in Makkah Al-Mukkaramah (Al-Harthi et al, 2006), $32.3 \%$ in Najran were seropositive for toxoplasmosis by ELISA-IgG (El-Shahawy et al, 2014). On the contrary, some studies showed higher levels of seroprevalence than the current study: $42.1 \%$ in Dammam District (Abbas et al, 1986) and 52.1\% in Asir Region (Al-Amari, 1994). In a study by AlHussainya et al. (2015) in Jeddah, T. gondiiIgG was $31.75 \%$ among schizophrenic patients and $25.64 \%$ in patients with major depressive disorders compared to an incidence of $14.55 \%$ in healthy ones.

Regarding other Arab Countries, Morsy et al. (1978) in Jordan reported positive toxoplasmin skin tests in children in the Royal Institute for Mentally Retarded Children.
Wishahy et al. (1975) in Egypt reported toxoplasmosis in children with some neurological manifestations and Rifaat et al. (1975) reported infantile toxoplasmosis and some neurological disorders. Mabrouk and Dahawi (1991) studied 42 meningoencephalitis patients with negative CSF cultures for common pathogenic bacteria. The seropositive Toxoplasma-IgG by IFA were $10 / 42$ (26\%). Clinical presentation and CSF changes were found with high antibody titers. They incriminated toxoplasmosis as an etiologic agent for meningo-encephalitis.

In United Arab Emirates, seroprevalance was $34 \%$ in blood donors (Uduman et al, 1998), 29.8\% seropositives in Doha, Qatar (Abu-Madi et al, 2008). In Libya $T$. gondii IgG antibodies in psychiatric patients was $50.3 \%$, \& $33 \%$ in control volunteers (Elsaid et al, 2014).

In Aden City, Yemen seropositive rate was 64.3\% (Muqbil and Alqubatii, 2014). Seroprevalences variability from an area to another, not only depended on climatic and geographical localities but also on cultural behaviors (Pappas et al, 2009).

In other studies comparing $T$. gondii in psychiatry patients to controls, great varieties were noted; at Durango City, Mexico, the prevalence of $T$. gondii infection in psychiatric inpatients was $18.2 \%$ which is significantly higher than in controls $8.9 \%$ (Alvarado-Esquivel et al, 2006). In Chinese psychiatric patients, it was $17 \cdot 3 \%$ while it was $12 \cdot 36 \%$ in controls (Cong et al, 2015). Koshy and Cabral (2014) in USA stated that brain-Toxoplasma interaction is critical to the symptomatic disease produced by Toxoplasma, but with little understanding of the cellular or molecular interaction between cells of the CNS and the parasite. All of the above mentioned studies showed evidence that $T$. gondii-IgG in neuropsychiatric patients was significantly higher than $T$. gondii-IgG in controls which agreed with the present data.

Some reports are linking Toxoplasma infection to psychiatric disorders with the fact 
that Toxoplasma infection alters the host's immunological status with oxidative stress producing toxic free radicals like reactive oxygen species and nitric oxide. These free radicles are involved in the pathophysiology of many psychiatric and neurodevelopmental disorders (Meyer et al, 2011). Nevertheless, there was no statistical difference between seroprevalence of IgM in neuropsychiatric patients and controls $P=0.497$. This was in accordance with the study of Cong et $a l, 2015$ which found that no relation between them. This confirmed the assumption of the role for latent and not recent infection of toxoplasmosis in neuropsychiatric disorder.

There is no significant difference when comparing each age group between studied and controls except for age group 40-49 and 50-59. The increase in patients' age went side by side with increase in the prevalence of Toxoplasma IgG (Cong et al, 2015; Owakowska et al, 2014). On the other hand; a Mexican study did not find any relation between age and prevalence of Toxoplasma IgG (Alvarado-Esquivel et al, 2006).

Working, education and socioeconomic status showed significant differences between the two groups. Being not working and having a low level of education is usually coexisting in most of the neuropsychiatric patients. This is mostly linked to patient infections exposure as these people might live in a poor environmental and sanitary condition which triggers their infections. When specific diagnoses of psychiatric diseases were analyzed, we found that most prevalent disease was schizophrenia. The prevalence of Toxoplasma IgG was statistically significant among schizophrenic patients compared to control group. This is in accordance with forty two studies analysis that carried out in 17 countries and reported that schizophrenia patients had increased seroprevalence of $T$. gondii than controls (Torrey et al, 2007).

In the present study, significant differences of Toxoplasma $\mathrm{IgG}$ were found in moderate depression and drug induced psychosis. Al-
Hussainya et al. (2015) reported that the level of Toxoplasma IgG was higher in depressed patients compared to controls. Interestingly all epileptic patients had positive IgG-antibodies against $T$. gondii with highly significant differences than controls. The relation between epilepsy and toxoplasmosis was strongly postulated. A previous study on this relation concluded that chronic toxoplasmosis infection might be an etiological factor for cryptogenic epilepsy (Yazar et al, 2003).

Linear regression bivariate analysis revealed that contact to cats and/or dogs and contact to soil were associated with high seroprevalence rate of Toxoplasma $\operatorname{IgG}$ than others. Eating raw or under cocked meat and positive history of blood transfusion were also correlated to increased serofrequency rate of Toxoplasma IgG. This finding is in accordance to other studies which prove the role of cats in disease transmission (Zemene et al, 2012). Contact with incriminated soil transmitted toxoplasmosis, mainly in Jazan (Aqeely et al, 2014) as that oocyst might present in soil which may be spread along with dusty winds (Seasonal Ghubrah) that is predominantly present in Jazan District.

Saleh et al. (2016) in Egypt reported several means of acquiring toxoplasmosis in humans: 1- Through vertical transmission from an infected mother to her fetus (Congenital). 2- Ingestion of infectious oocysts from the environment (usually from soil contaminated with feline feces), 3- Cleaning cat litter boxes. 4- Drinking unpasteurized goat milk or equine milk. 5- Ingestion of tissue cysts in meat from an infected animal, 6Eating unwashed raw vegetables or fruits. 7Blood transfusion or organ transplantation from an infected donor, (Acquired infection). 8- By needle-stick injuries that occurs accidentally as well as handling specimens that may contain viable organisms during laboratory investigations and experimental work. 


\section{Conclusion}

Toxoplasmosis is a worldwide distributed disease with a complex epidemiology. The risk of infection for humans depends on their contact with infective oocysts in a contaminated environment and on the amount of tissue cysts located within consumed meat.

In the present study, the psychiatric patients in Al-Amal Neuropsychiatry hospital, Jazan, had a significantly higher seroprevalence of $T$. gondii IgG than the controls. Thus, there might be a causal relationship between toxoplasmosis and the etiology of psychiatric diseases. The outcome data suggested that the contact with cat and/dogs indoors or outdoors and also contaminated soil contact might be the most important routes of $T$. gondii transmission in the studied psychiatric patients.

Disclosure: This study received support and funding from the Deanship of Scientific Research, Jazan University, Jazan, the Kingdom of Saudi Arabia.

\section{References}

Abbas, SA, Basalamah, A, Serebour, F, Alfonso, M, 1986: The prevalence of Toxoplasma gondii antibodies in Saudi women and the outcome of congenital infection among newborns in Saudi Arabia. Saudi Med. J. 7:346-54.

Abu-Madi, MA, Al-Molawi, N, Behnke, JM, 2008: Seroprevalence and epidemiolo-gical correlates of Toxoplasma gondii infections among patients referred for hospital-based serological testing in Doha, Qatar, Parasites and Vectors, 1, 39-44.

Ahmed, MM, 1992: Seroepidemiology of Toxoplasma infection in Riyadh, Saudi Arabia. J. Egypt. Soc. Parasitol. 22, 2:407-13.

Al-Amari, OM, 1994: Prevalence of antibodies to Toxoplasma gondii among blood donors in Abha, Asir Region, south-western Saudi Arabia. J. Egypt. Publ. Hlth. Assoc. 69, 1/2:77-88

Al-Harthi, SA, Jamaoom, MB, Ghazi, HO, 2006: Seroprevalence of Toxoplasma gondii among pregnant women in Makkah, Saudi Arabia.2006 Umm Al-Qura Univ. J. Sci. Med. Eng. 18, 2:217-27

Al-Hussainya, NH, Al-Saedib, AM, Al-lehaibib, JH, Al-lehaibib, YA, Al-Sehlib, YM, et al, 2015: Serological evidences link toxoplasmosis with schizophrenia and major depression disorder J. Microsc. Ultrastruct. 3:148-53.

Alvarado-Esquivel, C, Alanis-Quiñones, OP, Arreola-Valenzuela, MA, Rodríguez-Briones, A, Piedra-Nevarez, LJ, et al, 2006: Seroepidemiology of Toxoplasma gondii infection in psychiatric inpatients in a northern Mexican City. BMC Infect. Dis. 6:178-84.

Alvarado-Esquivel, C, Liesenfeld, O, Márquez-Conde, JA, Estrada-Martínez, S, Dubey, J P, 2010: Seroepidemiology of infection with Toxoplasma gondii in workers occupationally exposed to water, sewage, and soil in Durango, Mexico. J. Parasitol. 96, 5:847-50.

Alvarado-Esquive, C, Arrillo-Oropeza, D, Pacheco-Vega, SJ, Hernández-Tinoco, J, Salcedo-Jaquez, M, et al, 2015a: Toxoplasma gondii exposure in patients suffering from mental and behavioral disorders due to psychoactive substance use. BMC Infect. Dis. 15:172-8.

Alvarado-Esquivel, C, Sánchez-Anguiano, L F, Hernández-Tinoco, J, Arreola-Cháidez, E, López, J, Salcido-Meraz, KI, et al, 2015b: High seroprevalance of Toxoplasma gondii infection in female sex workers: A case control study Europ. J. Microbiol. Immunol. 5, 4:285-92

Aqeely, H, El-Gayar, EK, Perveen Khan, D, Najmi, A, Alvi, A, et al, 2014: Seroepidemiology of Toxoplasma gondii amongst pregnant women in Jazan Province, Saudi Arabia J Trop Med, doi.org/10.1155/2014/913950.

Carruthers, VB, Suzuki, Y, 2007: Effects of Toxoplasma gondii infection on the brain. Schizophr. Bull. 33:745-51.

Cong, W, Dong, W, Bai, L, Wang, TX, Ni, X T, et al, 2015: Seroprevalence and associated risk factors of Toxoplasma gondii infection in psychiatric patients: a case-control study in eastern China Epidemiol. Infect. 143, 3103-9.

Dubey, JP, 2010: Toxoplasmosis of Animals and Humans, 2nd edn. Boca Raton, Florida: CRC Press.

Elsaid, MMA, Azbedah, AG, El-Alem, DE, Alkout, A, 2014: The prevalence of Toxoplasma gondii infection in psychiatric patients in Tripoli, Libya. J. Amer. Sci. 10, 5: http://www.Jofamericanscience. Org.

El-Shahawy, IS, Khalil, MI, Bahnass, MM, 2014: Seroprevalence of Toxoplasma gondii in women in Najran City, Saudi Arabia. Saudi Med. J. 35, 9:1143-6.

Fabiani, S, Pinto, B, Bruschi, F, 2013: Toxoplasmosis and neuropsychiatric diseases: can 
serological studies establish a clear relationship? Neurol. Sci. 34:417-25

Fekadu, Al, Shibre, T, Cleare, AJ, 2010: Toxoplasmosis as a cause for behavior disorders-overview of evidence and mechanisms. Folia Parasitol (Paraha) 57, 2:105-13.

Flegr, J, 2015: Neurological and neuropsychiatric consequences of chronic Toxoplasma infection. Curr. Clin. Mic. Reports 2, 4:163-72.

Hamidinejat, H, Ghorbanpoor, M, Hosseini, H, Alavi, SM, Nabavi, L, et al, 2010: Toxoplasma gondii infection in first-episode and inpatient individuals with schizophrenia Int. J. Infect. Dis. 14, 11:978-81.

Immam, NFA, Azzam, EAA, Attia, AA, 2016: Seroprevalence of Toxoplasma gondii among pregnant women in Almadinah Almunawwarah KSA. J. Taibah Univ. Med. Sci. 11, 3:255-9.

Jones, JL，Kruszon-Moran，D，Wilson， M, McQuillan, G, Navin, T, McAuley, JB, 2001: Toxoplasma gondii infection in the United States: Seroprevalence and risk factors. Am. J. Epidemiol, 154, 4:357- 65.

Koshy, AA, Cabral, CM, 2014: 3-D imaging and analysis of neurons infected in vivo with Toxoplasma gondii. J. Vis. Exp. Dec 9;(94). doi: 10.3791/52237.

Meyer, U, Feldon, J, Dammann, O, 2011: Schizophrenia and autism: both shared and disorder-specific pathogenesis via perinatal inflammation. Pediatr. Res. 69:26-33.

Mabrouk, MA, Dahawi, HS, 1991: Toxoplas$m a$ antibodies in patients with meningoencephalitis. J. Egypt. Soc. Parasitol. 21, 2:547-51.

Morsy, TA, El Dasouqi, ST, Michael, SA, 1978: Toxoplasmin skin tests in mentally retarded children in Jordan. J. Egypt. Pub. Hlth. Assoc. 53, 1/2:87-90.

Muqbil, NA, Alqubatii, MA, 2014: Seroprevalence of toxoplasmosis among women in Aden city, Yemen. Arch. Biomed. Sci. 2, 2:42-50.

Nowakowska, D, Wujcicka, W, Sobala, W, Spiewak, E, Gaj, Z, et al, 2014: Age-associated prevalence of Toxoplasma gondii in 8281 pregnant women in Poland between 2004 and 2012. Epidemiol. Infect. 142, 3:656-61.

Pappas, G, Roussos, N, Falagas, ME, 2009: Toxoplasmosis snapshots: global status of Toxoplasma gondii seroprevalence and implications for pregnancy and congenital toxoplasmosis. Int. J. Parasitol. 39:1385-94.

Rifaat, MA, Wishahy, AO, Morsy, TA, Sadek, MSM, Hussein, D, 1975: Toxoplasmosis and some neurological disorders in Egypt. J. Egypt. Pub. Hlth. Assoc. 50, 1:1-10.

Rorman, E, Zamir, CS, Rilkis I, Ben-David, H, 2006: Congenital toxoplasmosis-prenatal aspects of Toxoplasma gondii infection. Reprod. Toxicol. 21:458-72.

Saleh, AMA, Al-Agroudi, MA, Morsy, TA, 2016: Occupational, nosocomial or hospital acquired toxoplasmosis. J. Egypt. Soc. Parasitol. 46, 2:407-18.

Torrey, EF, Bartko, JJ, Lun, ZR, Yolken, RH, 2007: Antibodies to Toxoplasma gondii in patients with schizophrenia: A meta-analysis. Schizophr. Bull. 33, 3:729-36.

Uduman, SA, Mohamed, HN, Bener, A, Dar, FK, 1998: The prevalence of Toxoplasma gondii specific IgG and IgM antibodies in blood donors in Al Ain, United Arab Emirates indicates a potential risk to recipients. J. Commun. Dis. 30, 4: 237-9.

Wang, PS, Aguilar-Gaxiola, S, Alonso, J, Angermeyer, MC, Borges, G, et al, 2007: Use of mental health services for anxiety, mood, and substance disorders in 17 countries in the WHO world mental health surveys. Lancet 8,370 (9590):841-50.

WHO, 1992: The ICD-10 Classification of Mental and Behavioral Disorders: Clinical Descriptions and Diagnostic Guidelines. Geneva, Switzerland.

WHO, 2001: World Health Report 2001. Mental Health: New Understanding, New Hope; World Health Organization, Geneva, 178, Switzerland.

Wishahy, AO, Rifaat, MA, Morsy, TA, EI Naggar, BA, 1975: Toxoplasmosis in children with some neurological manifestations. J. Trop. Med. Hyg. 75, 12:255-6.

Yazar, S, Arman, F, Yalçin, S, Demirtaş, F, Yaman, O, et al, 2003: Investigation of probable relationship between Toxoplasma gondii and cryptogenic epilepsy. Seizure 12, 2:107-9.

Zemene, E, Yewhalaw, D, Abera, S, Belay, T, Samuel, A, et al, 2012: Seroprevalence of Toxoplasma gondii and associated risk factors among pregnant women in Jimma town, Southwestern Ethiopia, BMC Infect. Dis. 12, 337, doi: 10. 1186/1471-2334-12-337

Zhou, P, Chen, Z, Li, H, Zheng, H, He, S, et al, 2011: Toxoplasma gondii infection in humans in China. Parasites Vectors 4, 1:165) doi: 10.1186/1756-3305-4 -165. 